\title{
PEMBUATAN APLIKASI PENJADWALAN KULIAH
}

\author{
1) Josep Dedy Irawan, ${ }^{2)}$ Emmalia Adriantantri \\ 1) Prodi Teknik Informatika, Fakultas Teknologi Industri, Institut Teknologi Nasional Malang \\ ${ }^{2)}$ Prodi Teknik Industru, Fakultas Teknologi Industri, Institut Teknologi Nasional Malang \\ Joseph@lecturer.itn.ac.id
}

\begin{abstract}
ABSTRAK
Dalam sebuah sistem pendidikan, penjadwalan kuliah merupakan suatu hal yang penting. Mengingat banyak faktor yang harus dipertimbangkan, agar jadwal proses bekajar mengajar dapat berjalan dengan baik dan lancar. Permasalahan yang sering muncul adalah terjadi kesamaan jadwal, dimana mata kuliah berbeda dengan mahasiswa yang sama dan dosen yang berbeda atau dosen sama dengan mahasiswa yang berbeda. Untuk itu dibuatlah sebuah aplikasi untuk menjadwalkan kuliah untuk mengatasi permasalahan yang telah diterangkan sebelumnya. Metode yang digunakan dalam penelitian ini adalah wawancara dan dokumentasi untuk memperoleh data-data yang diperlukan. Untuk selanjutnya pembuatan aplikasi dengan menggunakan bahasa pemrograman delphi Dari hasil pembuatan aplikasi ini maka dapat diperoleh jadwal kuliah yang lebih baik dibandingkan dengan penjadwalan kuliah sebelumnya.
\end{abstract}

Keyword : Jadwal Kuliah, Aplikasi

\section{Pendahuluan}

Dalam sebuah sistem pendidikan, penjadwalan kuliah merupakan suatu hal yang penting. Mengingat banyak faktor yang harus dipertimbangkan, agar jadwal proses bekajar mengajar dapat berjalan dengan baik dan lancar, sehingga mahasiswa dapat memperoleh ilmu dengan optimal. Permasalahan yang sering muncul adalah terjadi kesamaan jadwal, dimana mata kuliah berbeda dengan mahasiswa yang sama dan dosen yang berbeda atau dosen sama dengan mahasiswa yang berbeda. Untuk itu maka, penelitian ini bertujuan untuk membuat sebuah aplikasi untuk menjadwalkan kuliah untuk mengatasi permasalahan tersebut.

\section{Metode}

Metode yang digunakan dalam penelitian ini adalah wawancara dan dokumentasi untuk memperoleh data-data yang diperlukan, yaitu data mata kuliah prodi, dosen pengampu, hari aktif dan patokan perhitungan jam mengajar. Pengembangan sistem menggunakan tahapan analisis, perancangan, pemrograman, pengujian dan implementasi. Untuk selanjutnya, pembuatan aplikasi dengan menggunakan bahasa pemrograman delphi serta penerapan metode waterfall

Adapun penjelasan dari masing-masing tahapan sebagai berikut :

1. Analisis Kebutuhan

Tahapan yang dilakukan pada bagian ini adalah pengumpulan data pendukung seperti input apa saja yang dibutuhkan serta otput seperti apa yang diinginkan

\section{Desain Sistem}

Tahapan ini dirancang sistem yang akan dibuat, dari inputan yang dimasukkan ke dalam aplikasi proses apa yang akan dilakukan dalam hal ini perlu dirancang dari sisi aplikasi serta dari sisi database, serta perancangan aplikasi dibuat semudah mungkin dioperasikan oleh operator supaya menguraki resiko kesalah entry data

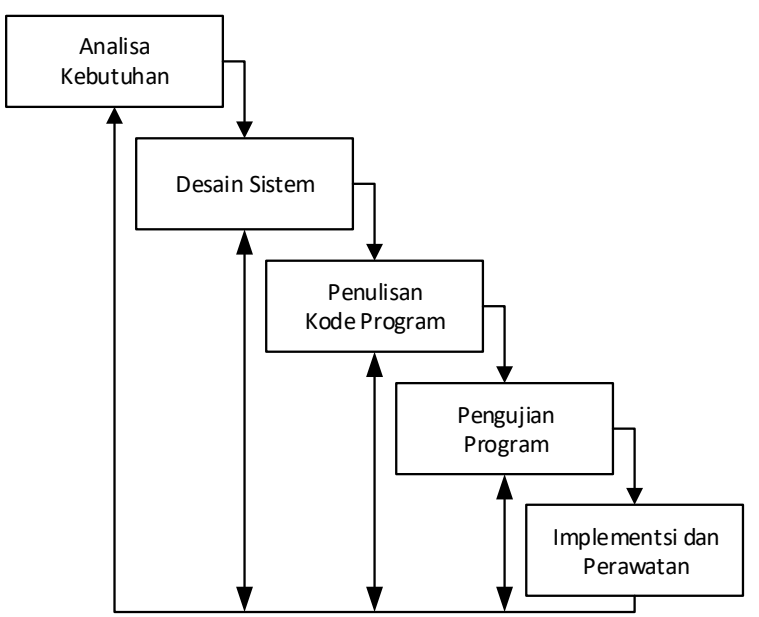

Gambar 1. Metode pembuatan aplikasi

3. Penulisan Kode Program

Tahapan penulisan program terlebih dahulu dilakukan penyiapan database, supaya tidak terjadi kesalahan disain maka harus dicermati setiap kemungkinan proses penyimpanan data yang akan terjadi. Setelah proses pembuatan database dilanjutkan dengan pembuatan program dengan menuliskan kode program sesuai desain yang telah dibuat sebelumnya 
4. Pengujian Program

Tahapan ini mempunyai peranan yang sangat penting sebelum sebuah aplikasi dijalankan, proses pengujian dilakukan dengan mengisikan data-data yang dibutuhkan, melakukan proses penjadwalan, melakukan pengecekan bentrok jadwal, serta memeriksa fungsi dan alur program sudah sesuai dengan desain atau belum.

5. Implementasi dan Perawatan

Tahapan ini merupakanan tahapan terakhir, dimana aplikasi mulai dijalankan, selama aplikasi dijalankan perlu dimonitor hasilnya, jika terdapat kesalahan dalam penulisan program maka tahapan pemeliharaan harus segera dilakukan supaya aplikasi dapat berjalan sesuai dengan keinginan.

\section{Hasil dan Pembahasan}

Yang perlu diperhatikan dalam pembuatan jadwal kuliah adalah :

1. Jadwal dosen tidak boleh bertabrakan

2. Jadwal mahasiswa tidak boleh bertabrakan

3. Jadwal ruang tidak boleh bertabrakan

Selain itu ada beberapa parameter lain yang harus dipertimbangkan yaitu :

1. Mata kuliah bisa memiliki kelas parallel, misalnya kelas A,B,C,D

2. Dosen bisa mengampu lebih dari satu mata kuliah dan beberapa kelas paralel

3. Jika dosen atau mahasiswa dalam satu hari mengikuti lebih dari satu kelas diharapkan dapat dilaksanakan secara berurutan, misalnya mata kuliah 3 SKS ditempuh jam ke 1-3 dan 47

Dari permasalah-permasalah diatas maka harus dirancang suatu aplikasi penjadwalan mata kuliah yang dapat mengecek secara otomatis jika terjadi bentrok terhadap jadwal mahasiswa, dosen maupun ruang kelas.

\section{Perancangan}

Langkah awal dari aplikasi ini adalah memasukkan data dosen, mata kuliah, Pembina mata kuliah serta peserta mata kuliah (mahasiswa), setelah memasukkan data awal tersebut proses penjadwalan dapat dilakukan, pada saat dilakukan proses penjadwalan jika terjadi bentrok aplikasi akan memberikan informasi siapa yang bentrok sehingga dapat jadwal dapat dipindahkan supaya tidak bentrok, setelah penjadwalan kuliah selesai dilakukan, maka dapat dilakukan pencetakan jadwal mengajar dosen, jadwal kuliah mahasiswa serta presensi perkuliahan.

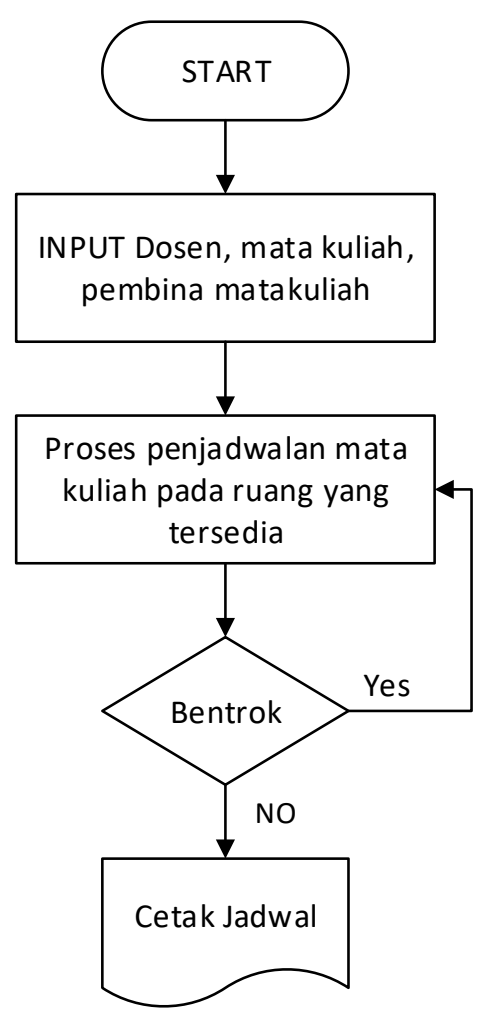

Gambar 2. Flowchart sistem

\section{Entity Relationship Diagram}

Dari gambar 3 dapat dilihat hubungan dari tabel yang digunakan dalam pembuatan aplikasi penjadwalan kuliah, tabel utama dari sistem ini adalah tabel jadwal, dimana tabel ini didukung oleh tabel mata kuliah, tabel peserta kuliah, tabel peserta, tabel dosen serta tabel mahasiswa.

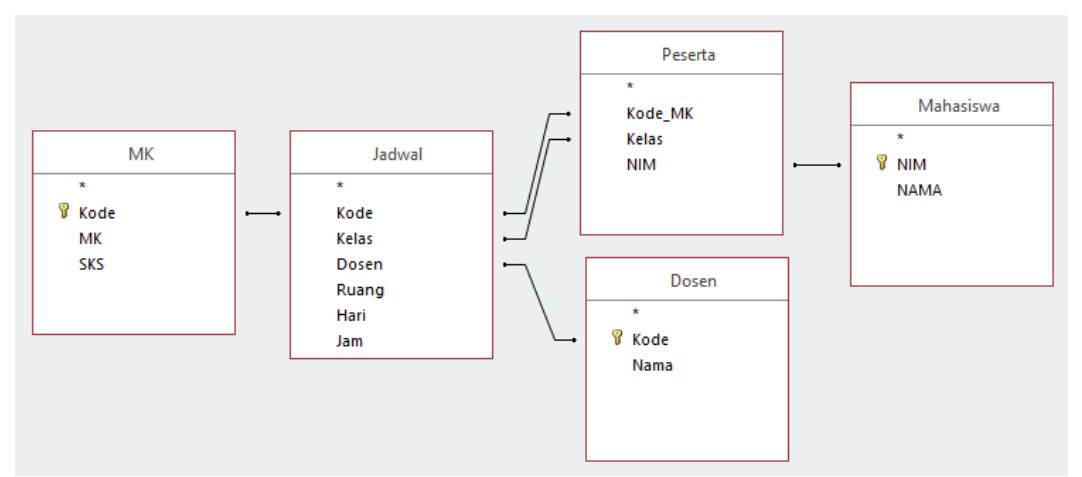

Gambar 3. Relasi database 


\section{Implementasi Software}

Tahap selanjutnya adalah implementasi dari program yang telah dibuat seperti pada gambar berikut ini.

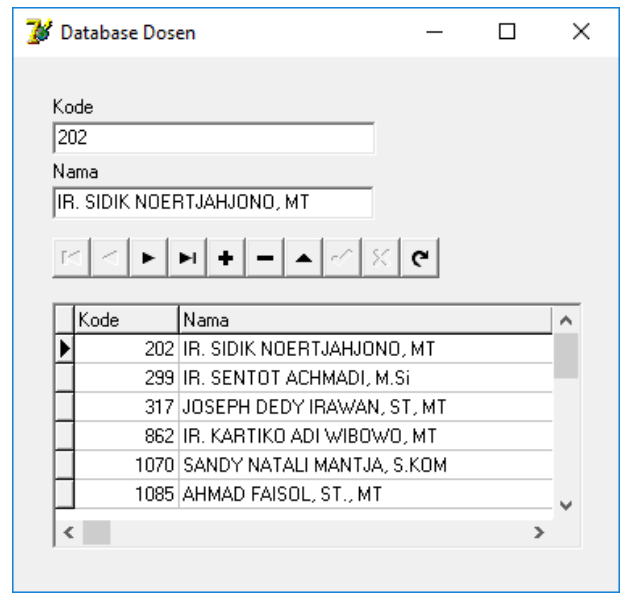

Gambar 4. Database Dosen

Tahap awal yang harus dilakukan adalah memasukkan data dosen, proses ini cukup dilakukan sekali dan akan digunakan berulang kali, jika ada penambahan dosen maka dosen baru ditambahkan ke database, sedangkan dosen yang lama tetap tidak perlu dientrykan lagi.

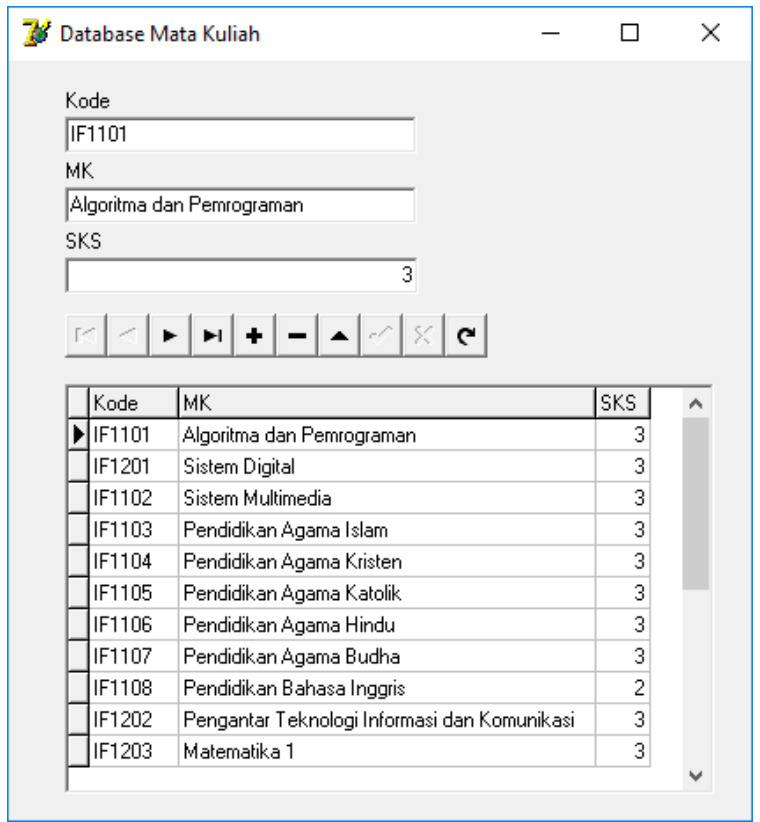

Gambar 5. Database Mata Kuliah

Langkah selanjutnya adalah memasukkan database mata kuliah, dimana database ini terdiri dari kode mata kuliah, nama mata kuliah dan SKS dari mata kuliah.

Setelah data mata kuliah dientrukan ke database langkah selanjutnya seperti dapat dilihat pada gambar 6 adalah proses memasukkan peserta di setiap mata kuliah, menu combo menunjukkan nama mata kuliah dan kelas, setalah penekanan tombol tambah akan muncul daftar nama mahasiswa, kemudian setelah mahasiswa dipilih maka mahasiswa tersebut akan terdaftar sebagai perserta mata kuliah tersebut.

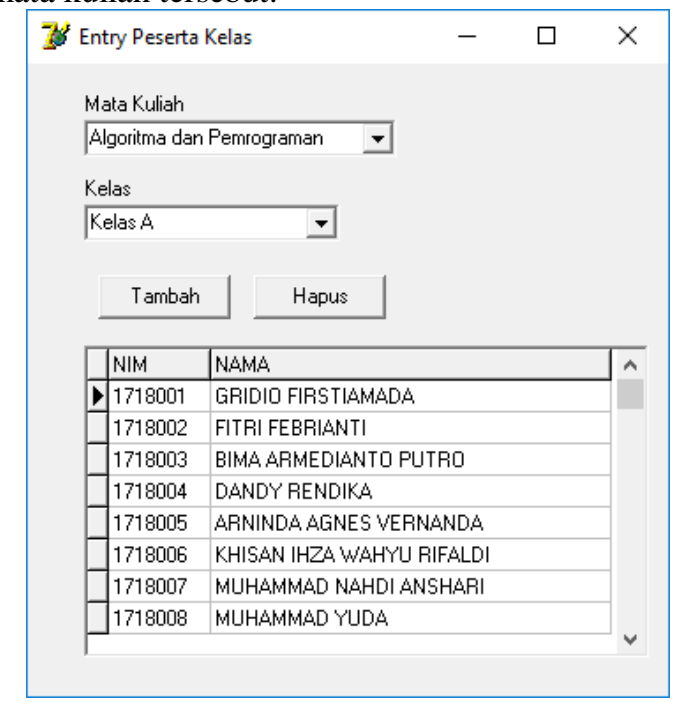

Gambar 6. Entry Peserta kuliah

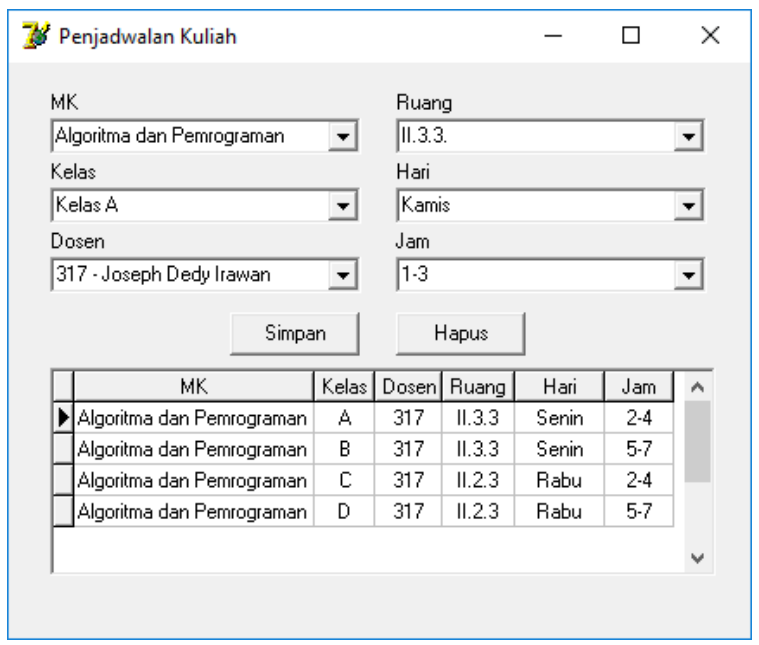

Gambar 7. Entry Jadwal kuliah

Proses selanjutnya adalah pemasukan jadwal kuliah yang terdiri dari combo mata kuliah, kelas, dosen, hari, jam dan ruang kuliah. Proses ini dilakukan satu per satu untuk semua mata kuliah dan semua kelas paralel.

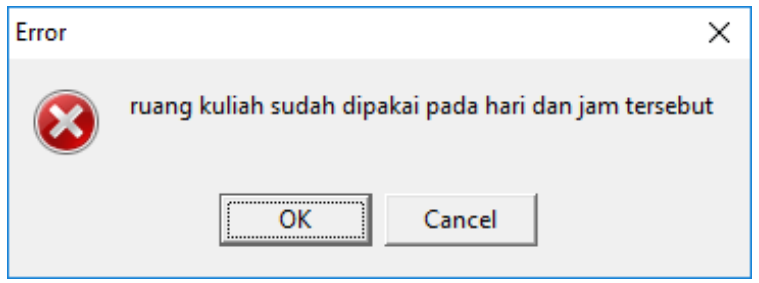

Gambar 8. Pesan kesalahan 
Pada saat penjadwalan jika terjadi bentrok mahasiswa, dosen atau ruang maka akan muncul pesan error yang menunjukkan kesalahan yang terjadi, dengan adanya pengecekan jadwal bentrok ini maka perkuliahan akan dapat berjalan dengan baik.

\section{Kesimpulan dan Saran}

Dengan pembuatan aplikasi penjadwalan kuliah ini, maka penjadwalan kuliah dapat dilakukan dengan lebih baik dan mengeliminasi terjadinya kesamaan jadwal atau bentrok jadwal mahasiswa, dosen dan ruang kuliah antara mata kuliah satu dan lainnya.

\section{Daftar Pustaka}

Josi, A. 2017. Implementasi Algoritma Genetika Pada Aplikasi Penjadwalan Perkuliahan Berbasis Web Dengan Mengadopsi Model Waterfall (Studi Kasus: STMIK Prabumulih). Jurnal Informatika:Jurnal Pengembangan IT (JPIT), Vol. 02, No. 02, Juli 2017

Rahim A. 2017. Perancangan Aplikasi E-informasi dan Jadwal Perkuliahan Berbasis Mobile Android. PROCESSOR Vol. 12, No. 1, April 2017

Romadhoni, E et al. 2015. Implementasi Model Waterfall Pada Pengembangan Sistem Informasi Alumni SMKN 1 Jenangan
Ponorogo. Seminar Nasional Sistem Informasi Indonesia, 2-3 November 2015

Rosyadi, R dan Sakuri. 2011. Sistem Informasi Jadwal Perkuliahan Berbasis Short Message Service Dengan Menggunakan PHP Hipertext Preprocessor di STMIK Amikom Purwokerto Jurnal Telematika Vol. 4 No.2 Agustus 2011.

Romadhoni, E et al. 2015. Implementasi Model Waterfall Pada Pengembangan Sistem Informasi Alumni SMKN 1 Jenangan Ponorogo. Seminar Nasional Sistem Informasi Indonesia, 2-3 November 2015

Toscany, A dan Rusdianto R. 2017. Pengembangan Sistem Penjadwalan Kuliah Menggunakan Algoritma Genetik (Studi Kasus : Pascasarjana Universitas Jambi). Jurnal Manajemen Sistem Informasi Vol.2, No.2, Juli 2017.

Usada, E et al. 2012. Rancang Bangun Sistem Informasi Jadwal Perkuliahan Berbasis Jquery Mobile Dengan Menggunakan PHP dan MySQL, Jurnal Infotel Volume 4 Nomor 2 November 2012

Widyaningtyas, T. 2012. Desain Dan Implementasi Jurnal Perkuliahan Berbasis Web Pada Jurusan Teknik Elektro Fakultas Teknik Universitas Negeri Malang. TEKNO, Vol: 17, Maret 2012, ISSN: 1693-8739 